\title{
Effects of Different Packaging Materials on Storage Quality of Crisp Plum
}

\author{
Benjiao Li ${ }^{1, *}$, Song $\mathrm{Li}^{1}$, Huaiyu Yuan ${ }^{2}$, Binrong Ma ${ }^{1}$, Yong Jing ${ }^{1}$, Zheming Zhang ${ }^{1}$, Zhijia Li $^{1}$, Dequan Zeng ${ }^{1}$ \\ ${ }^{1}$ Dazhou Academy of Agricultural Sciences, Dazhou, Sichuan, China \\ ${ }^{2}$ Institute of Agro-products Processing Science and Technology, Chengdu, Sichuan, China
}

\begin{abstract}
This experiment uses "Bashan crisp plum" as the material, uses nano-bags and spontaneous modified atmosphere preservation bags for packaging, combined with 1-MCP fumigation treatment, and stores in a cold storage at $1 \pm 1.5^{\circ} \mathrm{C}$. The physiological and biochemical measurements are measured every 15 days Indicators to discuss the low-temperature storage effects of different packaging materials. The results showed that the use of nano-bags and air-permeability of $3000 \mathrm{~mL} / \mathrm{bag} / 24 \mathrm{~h}$ modified atmosphere packaging can reduce fruit rot, delay the yellowing of the peel, better maintain the fruit texture and organic acid content, and better maintain the original fruit.
\end{abstract}

\section{Introduction}

"Bashan crisp plum" is an excellent variety formed through directional cultivation in the long-term production practice of planting plums. It passed the Sichuan Crop Variety Certification in December 2011. It has a crisp, sweet taste, high soluble solid content, and flavor. Unique and other advantages ${ }^{[1]}$, it has become the second major fruit grown in Dazhou City, and has gradually developed into a new growth point for rural support industries and rural economy in Xuanhan County, Dazhou City. However, with the increase in output and area, part of the fruit will be stored in order to avoid concentrated listing on the one hand and to increase the added value of the industrial economy on the other hand. However, there are still few studies on the postharvest storage technology of Bashan crisp plum.

1-MCP and spontaneous modified atmosphere packaging are currently commonly used commercial freshkeeping technologies for fruits and vegetables, which can better maintain the commercial quality of fruits and effectively extend the storage period ${ }^{[2-4]}$. However, there is still no relevant report on the suitable plastic wrap treatment technology for Bashan crisp plum. This study intends to analyze and compare the effects of different packaging materials combined with 1-MCP slow-release agent treatment on the quality of postharvest fruits, and initially screen out the best preservation film suitable for storage of Bashan crisp plums, which is a necessary theory for effectively prolonging the storage period of fruits And technical support.

\section{Materials and methods}

\section{1 materials and processing}

The samples for this experiment were collected in Huaguo Mountain, Miao'an Township, Tongchuan District, Dazhou City. The samples are required to have uniform color and size, consistent maturity, no disease and no mechanical damage. They are transported back to the Dazhou Academy of Agricultural Sciences after harvest on the same day and immediately precooled to dissipate field heat. After the pre-cooling is completed, three packaging materials are used for processing, namely nano fresh-keeping bags and modified atmosphere fresh-keeping bags (air permeability $3000 \mathrm{~mL} / \mathrm{bag} / 24 \mathrm{~h}$, air permeability $20000 \mathrm{~mL} / \mathrm{bag} / 24 \mathrm{~h}$ ). Each packaging bag contains about $5 \mathrm{~kg}$ of green crispy plums and counts them separately. Each treatment is stored in a freezer at $1 \pm 1.5^{\circ} \mathrm{C}$, the packaging bag is not tied, and the 1-MCP is used for fumigation for 8-12 hours. mouth. Each treatment was repeated 3 times, and samples were taken every 15 days to investigate the fruit rot rate and quality changes.

\section{2 measurement indicators and methods}

Decay rate. The fruit surface is softened, dented and shrunken, the fruit surface is water-soaked plaques, fluid, mold, rot and other phenomena are used as the basis for judging rot. Pick out the rotten fruits and count them, and calculate the formula: rotten rate $=$ (number of rotten fruits/total number of fruits) $\times 100 \%$. 
Peel color. A 3nh precision colorimeter was used to measure two symmetrical points at the equator of the fruit, where the $\mathrm{L}^{*}$ value represents the change in the brightness of the fruit from bright $\left(\mathrm{L}^{*}=100\right)$ to black $\left(\mathrm{L}^{*}=0\right)$. The $\mathrm{a}^{*}$ value represents the color change from green $\left(-\mathrm{a}^{*}\right)$ to red $\left(+\mathrm{a}^{*}\right)$. The larger the absolute value, the heavier the corresponding green and red. The $b^{*}$ value represents the change between yellow and blue. The $\mathrm{h}^{\circ}$ value indicates the color angle, where $0^{\circ}$ indicates red-purple, $90^{\circ}$ indicates yellow, $180^{\circ}$ indicates blue-green, and $270^{\circ}$ indicates blue.

Hardness, soluble solids, acidity. The hardness is measured by the GY-1 fruit hardness meter at the symmetrical two-point peeling hardness of the fruit at the equator; the soluble solids are measured by a hand-held brix meter; the acidity is measured by the acidity meter.

\subsection{Data processing}

Use Excel 2007 for data statistics and graphing.

\section{Results and analysis}

\subsection{The influence of different packaging materials on the rot rate of green crisp plum}

Due to the high water content of the green crisp plum fruit, coupled with the continuous decline in resistance during storage, the fruit is susceptible to mold infection and rot, causing the rot rate to continue to rise. The effect of different packaging materials on the rot rate of green crisp plums is shown in Figure 1. It can be seen from Figure 1 that when stored for 15 days, the green crisp plums of each treatment group began to rot. Due to condensation in the modified atmosphere preservation bag, the decay rate was higher than that of the nano bag packaging. The decay rate of green crisp plums increases with the extension of storage time. During the same storage period, the decay rate of the fruits packaged in a modified atmosphere bag with an air permeability of $20000 \mathrm{~mL} / \mathrm{bag} / 24 \mathrm{~h}$ is higher than that with an air permeability of $3000 \mathrm{~mL} / \mathrm{bag} / 24 \mathrm{~h}$. There is no significant difference in the decay rate of the air permeability of $3000 \mathrm{~mL} / \mathrm{bag} / 24 \mathrm{~h}$ and the nanobag. When stored for 60 days, the decay rate of the modified atmosphere fresh-keeping bag with an air permeability of $20000 \mathrm{~mL} / \mathrm{bag} / 24 \mathrm{~h}$ increased significantly by up to $5.63 \%$, which was $2.73 \%$ higher than that of the fruit packaged in nano-bags.

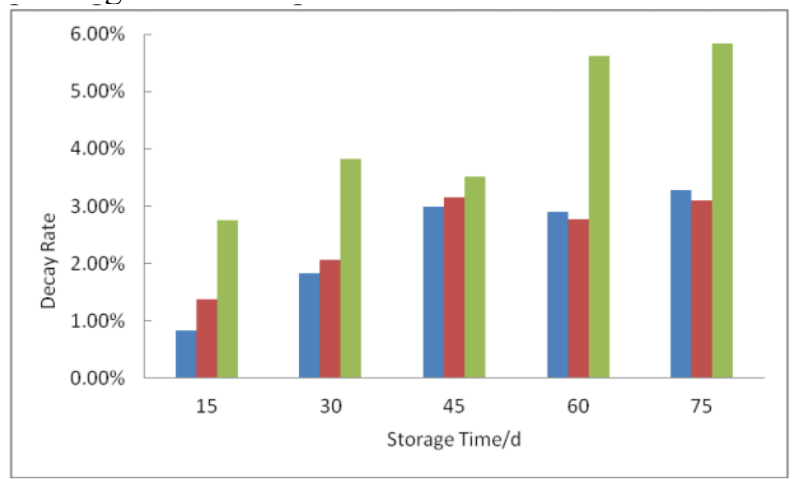

Fig. 1. The influence of different packaging materials on the rot rate of green crisp plum
(Note: In the figure, blue represents nano-bag packaging, red represents a modified atmosphere storage bag with an air permeability of $3000 \mathrm{~mL} / \mathrm{bag} / 24 \mathrm{~h}$, and green represents a modified atmosphere storage bag with an air permeability of $20000 \mathrm{~mL} / \mathrm{bag} / 24 \mathrm{~h}$, the same below.)

\subsection{The effect of different packaging materials on the color of green crisp plum peel}

The effect of different packaging materials on the color of green crisp plum peel is shown in Figure 2. It can be seen from Figure 2 that with the extension of storage time, the brightness ( $\mathrm{L}^{*}$ value) of all processed fruits gradually decreased. At 15 days, the air permeability of the airconditioning bag with an air permeability of $20000 \mathrm{~mL} / \mathrm{bag} / 24 \mathrm{~h}$ decreased rapidly, and then decreased slowly. This is due to the fact that there are more water droplets in the air-conditioned fresh-keeping bag with an air permeability of $20000 \mathrm{~mL} / \mathrm{bag} / 24 \mathrm{~h}$ when the green crispy plum is stored for 15 days after processing. The $\mathrm{a}^{*}$ value represents the color change from green $\left(-a^{*}\right)$ to red $\left(+\mathrm{a}^{*}\right)$. The larger the absolute value, the heavier the corresponding green and red. It can be seen from the figure that the absolute value of $\mathrm{a}^{*}$ keeps decreasing during the storage of green crispy plums, indicating that green crispy plums gradually lose their original green color. Green crispy plums are packaged in nano-bags and air-permeability modified atmosphere bags with $3000 \mathrm{~mL} / \mathrm{bag} / 24 \mathrm{~h}$. When the difference in $\mathrm{a}^{*}$ value is small. The $b^{*}$ value represents the change between yellow and blue. It can be seen from the figure that the green crisp plum gradually turns yellow during storage. From the analysis of the test data, the nano bag and the air-permeability of $3000 \mathrm{~mL} / \mathrm{bag} / 24 \mathrm{~h}$ can maintain the stability of the peel color better than that of the airpermeability of $20000 \mathrm{~mL} / \mathrm{bag} / 24 \mathrm{~h}$.

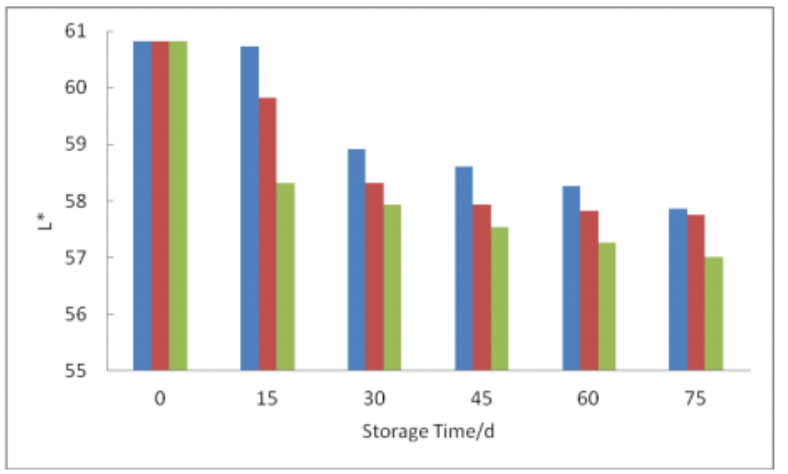



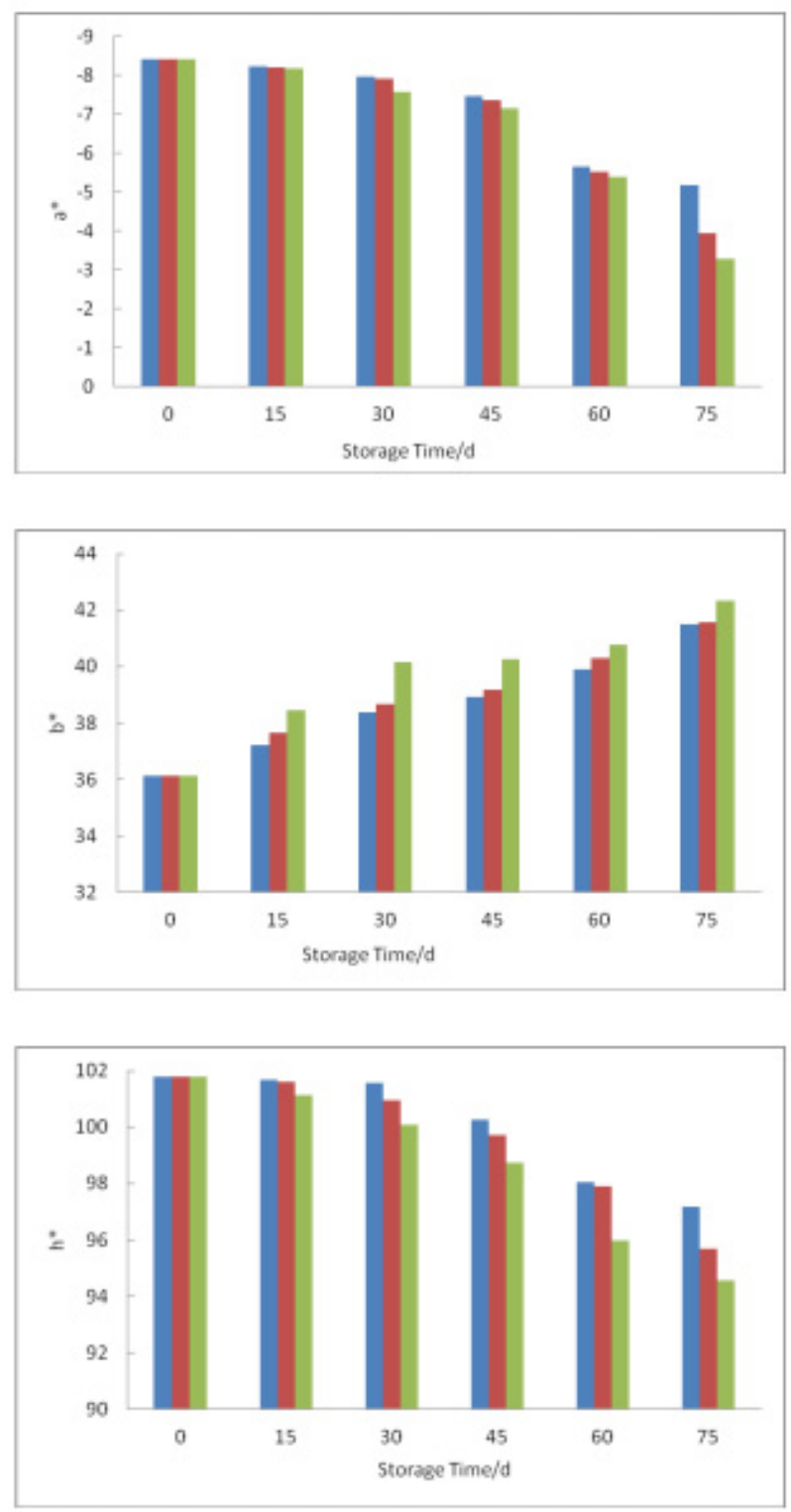

Fig. 2. The effect of different packaging materials on the color of green crisp plum peel

\subsection{The influence of different packaging materials on the hardness, soluble solids and acidity of green brittle plum}

The influence of different packaging materials on the hardness, soluble solids and acidity of green brittle plums is shown in Figure 3. It can be seen from Figure 3 that with the extension of the storage period, the hardness and soluble solid content of green brittle plums gradually decrease, and the acidity gradually increases. However, whether it is hardness, soluble solids or acidity, the air permeability of $20000 \mathrm{~mL} / \mathrm{bag} / 24 \mathrm{~h}$ is compared with nanobags and the air permeability of $3000 \mathrm{~mL} / \mathrm{bag} / 24 \mathrm{~h}$. The changes are faster. At the same time, there is little difference between the nano bag and the modified atmosphere bag with an air permeability of $3000 \mathrm{~mL} / \mathrm{bag} / 24 \mathrm{~h}$.
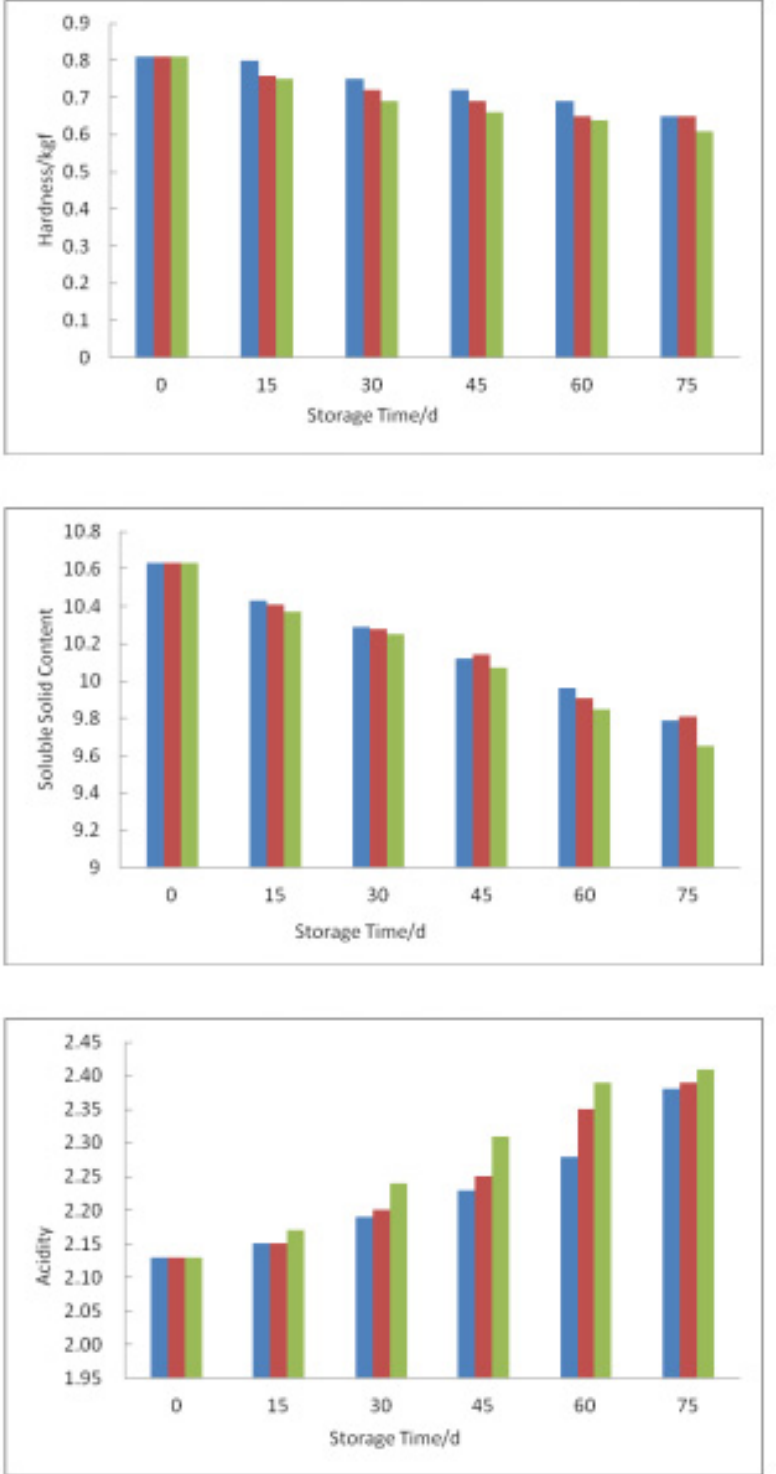

Fig. 3. The effect of different packaging materials on the hardness, soluble solids and acidity of green brittle plum

\section{Summary and discussion}

The harvested fruits and vegetables are still undergoing physiological activities such as breathing. Maintaining proper $\mathrm{O} 2, \mathrm{CO} 2$, water vapor and other gas content in the packaging bag can slow down the ripening and corruption of fruits and vegetables. When the $\mathrm{O} 2$ content in the packaging bag is less than $3 \%$ or the $\mathrm{CO} 2$ content is greater than $10 \%$, the fruits and vegetables will undergo anaerobic respiration and produce volatile substances such as ethanol and acetaldehyde, causing anaerobic oxygen damage and peculiar smell. The spontaneous modified atmosphere packaging is a simple modified atmosphere storage method commonly used in commerce. It uses the fruit's own respiration metabolism to reduce the oxygen concentration in the packaging bag and increase the carbon dioxide concentration, thereby further inhibiting the physiological metabolism of the fruit and delaying the fruit. Aging ${ }^{[5]}$.

As an ethylene antagonist, 1-MCP plays an important 
role in the preservation of many horticultural products ${ }^{[6]}$. This experiment analyzes and compares the effects of different plastic wraps on the postharvest storage quality of green crispy plums, screens the best wraps suitable for crispy plums, combines the early 1-MCP fumigation and low temperature treatment, and initially proposes the best postharvest green crispy plums Storage and preservation technology, improve preservation effect and prolong storage period. The results showed that the use of nanobags and air-permeability of $3000 \mathrm{~mL} / \mathrm{bag} / 24 \mathrm{~h}$ modified atmosphere packaging can reduce fruit rot, delay the yellowing of the peel, better maintain the fruit texture and organic acid content, and better maintain the original fruit. Have flavor. In summary, when green crisp plums are stored at low temperature after harvest, they can be packaged in nano-bags or modified atmosphere freshkeeping bags with an air permeability of $3000 \mathrm{~mL} / \mathrm{bag} / 24 \mathrm{~h}$, combined with 1-MCP fumigation treatment.

\section{References}

1. R.G. Gong, J.L. Ding, G.L. Zhang. Studies on physiological radiation spectrum and photosynthetic properties as well as fruit quality of Prunus americanc at different altitudes [J]. Journal of Sichuan Agricultural University, 2010, 28(04): 454-458.

2. Cheng Y, Liu L, Zhao G, et al. The effects of modified atmosphere packaging on core browning and the expression patterns of PPO and PAL genes in 'Yali' pears during cold storage[J]. LWT - Food Science and Technology, 2015, 60(2):1243-1248.

3. Wang Y, Sugar D . Internal browning disorder and fruit quality in modified atmosphere packaged 'Bartlett' pears during storage and transit[J]. Postharvest Biology \& Technology, 2013, 83:72-82.

4. Xie X , Song J , Wang Y, et al. Ethylene synthesis, ripening capacity, and superficial scald inhibition in 1MCP treated 'd'Anjou' pears are affected by storage temperature[J]. Postharvest Biology \& Technology, 2014, 97:1-10.

5. Jia Xiaohui, Wang Wenhui, Tong Wei, et al. Effects of spontaneous modified atmosphere packaging on postharvest physiology and storage quality of Korla fragrant pears[J]. Chinese Agricultural Sciences, 2016, 49(024):4785-4796.

6. Lum G B , Deell J R, Hoover G J , et al. 1Methylcylopropene and controlled atmosphere modulate oxidative stress metabolism and reduce senescence-related disorders in stored pear fruit[J]. Postharvest Biology \& Technology, 2017, 129:52-63. 